\title{
A Tradução Literária e o Polacolocopaca
}

\author{
Ivan Justen Santana
}

Antes de mais nada, esclareçamos que polacolocopaca é uma das muitas alcunhas dadas ao poeta curitibano Paulo Leminski (1944-1989). Salvo engano, foi o artista plástico Rettamozo quem criou esse sonoro apelido.

Para maiores informaçōes sobre a vida e obra de Leminski, consulte-se Envie meu dicionário', livro lançado recentemente, contendo cartas do poeta curitibano a Régis Bonvicino e diversos textos afins, inclusive a mais completa bibliografia de Leminski já organizada até o momento, reunida por Tarso M. de Melo.

Além de poeta, o polacolocopaca foi professor de cursinho pré-vestibular, redator publicitário, romancista, crítico cultural, compositor de música popular, e tradutor de obras literárias.

Como tradutor, Leminski publicou nove livros, vertendo os mais variados autores: desde o divertido prosador romano Petrônio, contemporâneo de Nero, até o não menos animado John Winston Lennon, aquele mesmo que fez parceria com um certo McCartney.

Lennon, em 1964 e 65, então com vinte e poucos anos e em meio à ascensão de sua banda de rock, publicou dois livros de textos literários pra lá de esquisitos, In His Own Write e ASpaniard In The Works, os quais Leminski lançou sob o título de Um Atrapatho No Trabalho, pela Brasiliense, em 1985.

Em todas as suas traduçōes o polacolocopaca brinda o leitor com um posfácio, no qual faz obsenvações sobre o autor e o 
texto original, e sobre seu trabalho tradutório. Já nesses posfácios podemos notar como é flexível a sua concepção teórica sobre o assunto.

No entanto, é num pequeno artigo chamado Trans/parale$\operatorname{las}^{2}$ que ele nos fala exclusivamente sobre teoria. Esse texto veio a propósito de um soneto de Euclides da Cunha, escrito em 1905, que Leminski vê como uma tradução de outro famoso soneto do poeta parnasiano Raimundo Correia.

Ao invés de ensaiar qualquer paráfrase, acho melhor transcrever, visto que o trecho que nos interessa é relativamente curto:

Traduzir de uma língua para outra é apenas um caso particular de tradução. A possibilidade de tradução está na própria raiz da natureza do signo que, diz Peirce, é "qualquer coisa que possa ser entendida através de outros signos", numa definição tautológica, bem ao gosto do neo-positivismo.

Sendo assim, pode-se entender como "tradução" todas as aproximaçōes do tipo da paródia (= canto paralelo), que tem intuitos burlescos, da paráfrase, que tem intençōes sérias, da adaptação (de um texto para o cinema ou o teatro), da diluição de uma mensagem original em (quase)-similares, mais ou menos afastados do seu protótipo.

São da mesma natureza todos os fenômenos que afetam à área da "influência", na literatura e na arte comparadas. Machado.

Influência de Sterne em Machado de Assis, traduçōes de

Influência do realismo socialista em Jorge Amado.

Influência da poesia espanhola (a quadra em rimas toantes) em João Cabral.

Traduções.

Mais literais, mais "espirituais" (conforme o "espírito", não a letra) a vida da cultura é um processo de traduções contínuas e constantes, em que traduções se transformam em novos originais, por sua vez, traduzidos, para repertórios mais altos ou mais baixos, vindo a constituir originais novos, e assim por diante. 
Queremos destacar aqui a vertigem que pode ser sentida ao refletir com o poeta: "a vida da cultura é um processo de traduções contínuas". Podemos então perceber (quase como um frio na barriga ao cair de súbito) que todas as obras literárias, e enfim, todas as palavras são, em última instância, traduçōes.

Desenvolvendo uma tal perspectiva, que puxa todas as brasas para a sardinha dos estudiosos da tradução, vemos que a cultura de um povo se forma e evolui através desse processo contínuo de traduções. Dialeticamente, quanto mais elementos emprestados são tomados, mais criações "novas" são feitas.

Vale lembrar, a essa altura, o ensaio de Otávio Paz, Literatura e literalidade ${ }^{3}$, o qual nos desperta a mesma vertigem diante da centralidade da tradução na evolução da cultura humana. Paz começa da seguinte forma:

Aprender a falar é aprender a traduzir; quando a criança pergunta à mãe o significado desta ou daquela palavra, o que realmente the pede é que traduza em sua linguagem o termo desconhecido. A tradução dentro de uma língua não é, nesse sentido, essencialmente diferente da tradução entre duas línguas, e a história de todos os povos repete a experiência infantil (...)

Ele então discorre sobre como antigamente a tradução era vista como a prova da universalidade da linguagem, e na idade moderna passou a mostrar as diferenças entre as culturas dos povos "civilizados" e "selvagens". Concluindo a primeira parte de seu ensaio, Paz mostra que a visão antiga e a moderna se complementam:

(...) Num extremo, o mundo nos aparece como uma coleção de heterogeneidades; no outro, como uma superposição de textos, cada qual ligeiramente distinto do anterior: traduções de traduções de traduçōes. Cada texto é único e, simultaneamente, é a tradução de outro texto. Nenhum texto é inteiramente original, 
porque a própria linguagem, na sua essência, já é uma tradução: primeiro, do mundo não-verbal e, depois, porque cada signo e cada frase traduzem outro signo e outra frase. Mas esse raciocínio pode ser invertido sem perder a validade: todos os textos são originais porque cada traduçāo é diferente. Cada tradução é, até certo ponto, uma invenção, e assim constitui um texto único.

Nada melhor que partir para poemas e traduções que ilustrem todas essas teorizações. Vamos começar com o que em princípio seria um texto original, uma famosa ode do poeta latino Horácio. É a ode 11 do Liber primus, da qual foi extraído o lema Carpe diem (aproveite o dia).

Quintus Horatius Flaccus (65 a.C. - 8 a.C.) chegou a publicar em vida seus livros de odes. Podemos, então, tentar reproduzir aqui como foi originalmente lançada sua ode 11, em rolo de pergaminho. $O$ ideal seria ouvi-lo declamá-la (ou cantá-la), que essa sim seria (ou não?) sua forma original.

Em todo caso, mesmo o texto a seguir, que busca ser o mais fiel possível em relação à publicação original, é uma espécie de tradução. Os pergaminhos eram caligrafados em letras maiúsculas, e cada edição era única em suas irregularidades. Curiosamente, eram os leitores quem normalmente pontuava o texto, durante a leitura, já que os versos vinham escritos em linha, sem separação de palavras. Essa primeira pontuação consistia apenas de pontos entre cada palavra, para facilitar a compreensão da frase latina, cheia de inversões sintáticas. A ode 11 do Liber primus, num rolo de pergaminho, seria, após uma primeira leitura, mais ou menos assim:

TU·NE·QUAESIERIS·SCIRE·NEFAS·QUEM·MIHI·QUEM·TIBI FINEM-DI-DEDERINT-LEUCONOE-NEC·BABYLONIOS TEMPTARIS·NUMEROS-UT'MELIUS·QUICQUID·ERIT·PATI SEU.PLURIS.HIEMES.SEU.TRIBUIT-IUPPITER -ULTIMAM QUEF-NUNC·OPPOSITIS·DEBILITAT·PUMICIBUS.MARE 


\section{TYRRHENUM·SAPIAS·VINA.LIQUES·ET'SPATIO·BREVI} SPEM.LONGAM.RESECES.DUM.LOQUIMUR.FUGERITIINVIDA EETAS.CARPE.DIEM-QUAM.MINIMUM-CREDULA.POSTERO

Para socorro dos leitores que não são latinistas, vejamos uma primeira tradução, feita por mim em versão interlinear, para ser possivel confrontar diretamente os versos e resolver essa pedra de roseta, seguindo palavra por palavra a poesia densa de Horácio.

TU·NE·QUAESIERIS·SCIRE·NEFAS·QUEM·MIHI·QUEM·TIBI tu.não.inquiras.conhecer.é sacrilégio.qual.a mim.qual.a ti FINEM-DI-DEDERINT'LEUCONOE-NEC·BABYLONIOS fim.os deuses.consagraram. Leuconoé.nem.babilônios TEMPTARIS·NUMEROS·UT·MELIUS·QUICQUID·ERIT·PATI experimentes.números.quando.melhor.o que quer que.seja.tolerar SEU.PLURIS·HIEMES·SEU·TRIBUIT-IUPPITER-ULTIMAM quer.muitos.invernos.quer.concedeu.Júpiter.o último QUE.NUNC·OPPOSITIS·DEBILITAT·PUMICIBUS-MARE que.agora.contra.abate.os rochedos.o mar TYRRHENUM·SAPIAS·VINA.LIQUES·ET·SPATIO·BREVI Tirreno.sábia.os vinhos.coe.e.em espaço.curto SPEM.LONGAM.RESECES.DUM.LOQUIMUR.FUGERITIINVIDA . a esperança.longa.cortes.enquanto.falamos.foge.invejosa EETAS.CARPE-DIEM-QUAM-MINIMUM-CREDULA-POSTERO a idade.colhe.o dia de hoje.quanto.o mínimo.confiante.no de amanhã

Cabem aqui antes de mais nada as seguintes palavras de Otávio Paz, na seqüência do já citado ensaio:

As descobertas da antropologia e da lingüística não condenam a tradução, e sim certa idéia ingênua da tradução. Ou seja: a tradução literal, que em espanhol chamamos significativamente 
servil. Nāo digo que a tradução literal seja impossível, mas que nảo é uma tradução. É um dispositivo, geralmente composto por uma fieira de palavras, para nos ajudar a ler o texto em sua língua original. Algo mais próximo do dicionário que da traduçāo, que é sempre uma operação literária.

Sem discutir se isso é uma tradução ou não, o que fiz foi montar o que Paz chamou de dispositivo, e espero que os leitores possam através dele chegar um pouco mais perto da ode de Horácio.

Para quem quiser se arriscar a declamá-la, saibam que o metro dos versos é o asclepiadeu maior. É um metro composto por uma mistura de pés diferentes, e que graficamente seria:

$---u v-/ /-u v-/ /-u v-u v$

(Obs. : - = sílaba longa

$\mathrm{u}=$ sílaba breve

// = pausa maior )

Talvez seja mais fácil compreender e declamar a ode (com atenção aos enjambments entre os versos 1-2, 2-3, 5-6, 6-7 e 7 8) lendo-a na versāo que é publicada nas ediçōes modernas, com a pontuação colocada pelos especialistas em poesia latina:

Tu ne quaesieris, scire nefas, quem mihi, quem tibi

Finem Di dederint, Leuconoe, nec Babylonios

Temptaris numeros. Ut melius, quicquid erit, pati!

Seu pluris hiemes, seu tribuit luppiter ultimam,

Quae nunc oppositis debilitat pumicibus mare

Tyrrhenum. Sapias, vina liques, et spatio brevi

Spem longam reseces. Dum loquimur, fugerit invida

Aetas. Carpe diem, quam minimum credula postero. 
Os especialistas, no entanto, dirão o seguinte: essa ode é sem dúvida uma imitação livre ou paráfrase de um original grego. É o que diz Clement Lawrence Smith, professor de Harvard, numa ediçẩo norte-americana de $1903^{4}$.

Vemos então uma confirmação de como acontece o processo de formaçāo de uma cultura, e, poderíamos dizer também, de uma literatura: traduz-se um poema de outra literatura mais antiga, a qual fornece os modelos literários. A tradução se transforma em original, que por sua vez é traduzido, etc.

Conforme reconhece Smith, Horácio emprestou da lírica grega os metros, os temas, e mesmo versos inteiros de Alceu, Píndaro, Anacreonte e Safo, sem falar em poetas e poemas que desapareceram por completo, e assim não podem ser rastreados no texto de Horácio.

Mas há toda uma mística de "originalidade" na poesia. Os poetas passaram a ser proprietários de seus versos, e continuam donos de sua obra até dezenas de anos após a morte. Já quem quer que faça traduçōes de poemas é visto como um subalterno estrangeiro do poeta de tal ou qual país. Perde-se de vista que a poesia se desenvolve sem obedecer aos limites entre países e línguas, e que as traduçōes têm um papel central nesse desenvolvimento.

Ezra Pound, poeta e tradutor que sempre teve consciência de tudo isso, conforme mostra tanto nos seus textos críticos, quanto nas suas traduçōes, quanto nos seus poemas (e normalmente não se consegue diferenciar a obra de Pound dessa forma, sob risco de nāo compreendê-la), também fez sua tradução da ode $11^{5}$ :

Ask not ungainly askings of the end Gods send us, me and thee, Leucothoe;

Nor juggle with the risks of Babylon,

Better to take whatever, 
Several, or last, Jove sends, us. Winter is winter, Gnawing the Tyrrhene cliffs with the sea's tooth.

Take note of flavors, and clarity's in the wine's manifest.

Cut loose long hope for a time.

We talk. Time runs in envy of us,

Holding our day more firm in unbelief.

Pound comenta, em seu $A B C$ of reading, que a poesia de Horácio mostra tudo que um poeta pode aprender sem ter uma raiz literária em sua língua. $\bigcirc$ norte-americano percebia a lírica grega por trás das odes latinas, e faz questāo de dar uma pista disso em sua tradução, quando verte o nome de Leuconoé para Leucothoe. Esse nome, de origem grega (significaria algo como Branca, ou Nívea), foi latinizado por Horácio, e Pound lhe devolve a sonoridade grega.

Outra observação interessante de Pound tangendo a Horácio é que é possível aprender mais sobre a evolução do verso inglês lendo a série de traduçōes do poeta latino ao longo da história (desde 1650 elas são publicadas na imprensa inglesa) do que através das obras "originais" dos poetas ingleses. Ponto para os estudiosos da tradução, novamente.

Sobre a versāo da ode 11 feita por Pound, vamos deixar que Paulo Rónai dê seu parecer (quem melhor que ele para criticar uma traduçāo?). Em A Tradução Vivida ${ }^{6}$ Rónai comenta sobre o "tratamento algo arrogante a que o poeta-tradutor submeteu o texto horaciano":

(...) Desapareceu o frêmito religioso encerrado em scire nefas; a curiosidade de desvendar o futuro que os deuses nos esconderam aqui já não é ímpia, apenas ungainly. Outra palavra essencial do poema, dum, "enquanto", desapareceu também. Enquanto Horácio fala com a amiga, fogem os minutos. Em Pound, apenas: "Nós conversamos". E esse Winter is winter, tão coloquial, não corresponde a nada no original. Por fim, a conclusão imortal, 
Carpe diem, dilui-se na versão. Sente-se que o tradutor relaxou por gosto o encadeamento das idéias, introduzindo no poema uma ambigüidade e indecisão modernas. Não serei provavelmente capaz de saborear a versão de Pound tão integralmente como um leitor de língua inglesa; mas, ainda que por ela perpasse a vibraçâo que lhe atribuem, custa-me considerá-la um padrão de traduçāo.

Voltemos, por fim, a Paulo Leminski, o qual por sua vez fez o seguinte com a ode $11^{7}$ :

nem me pergunte

saber não presta

Leuconoe

que fim os deuses nos preparam

nem arrisque

números de Babel

como se fosse o máximo - o que vier: fature

se o Pai te concedeu vários invernos

ou o último

agora o mar tyrrheno cepilha pedras de naufragar

filtre o vinho

sorva os côos

prazo breve

corta

a espera

a era já era

antes do tempo de dizer

estamos conversados

pega este dia

crer no próximo

nāo vale um nihil 
A disposição modernista dos versos na página faz com que variadas leituras dessa tradução possam ser feitas. É admirável como Leminski ao mesmo tempo em que usa uma linguagem que nos soa contemporânea, também emprega um vocábulo de sabor castiço: cepilha, do verbo cepilhar, que segundo o Aurélio tanto pode significar polir com limas finas, quanto aperfeiçoar, aprimorar, lapidar, ou ainda tornar sociável, civilizar.

Há que se destacar, ainda, para dar por terminado nosso trabalho, a palavra nihil, que não está no texto de partida, mas que joga o leitor em direção ao latim. A tradução de Leminski, curiosamente, se constitui num novo texto original nesse momento, não quando faz a passagem para a língua de chegada, mas justo quando volta à língua de partida.

1 BONVICINO, Régis (org.) Envie meu dicionário: cartas e alguma crítica. Säo Paulo : Ed. 34, 1999.

2 LEMINSKI, Paulo. Trans/paralelas. In Através 1. São Paulo: Martins Fontes, 1983.

3 PAZ, Otávio. Convergências. Rio de Janeiro: Rocco, 1991. pp. 148-160.

4 Em HORACE. The odes and epodes. Boston: Gim \& Co., 1903.

5 POUND, Ezra. The Translations of Ezra Pound. London : Faber and Faber, 1953. p.406.

6 RONAl, Paulo. A Traduçāo Vivida. Rio de Janeiro : Nova Fronteira, 1990. pp.144-146.

7 Publicado na revista REMATE DE MALES, 4, Território da tradução. Campinas: Unicamp, 1984. 